considered inoperable. Thus we have a proportion of one case in five considered inoperable clinically. This large proportion is not surprising, since the average duration of symptoms of the patients operated on was 2.3 years, while with 31 per cent. it was 3 or more years. The symptoms which caused us to consider the patient's condition as inoperable were (1) fluid in the abdomen; (2) edema of the extremities; (3) extreme emaciation and weakness; (4) evidence of metastasis; (5) cardiac

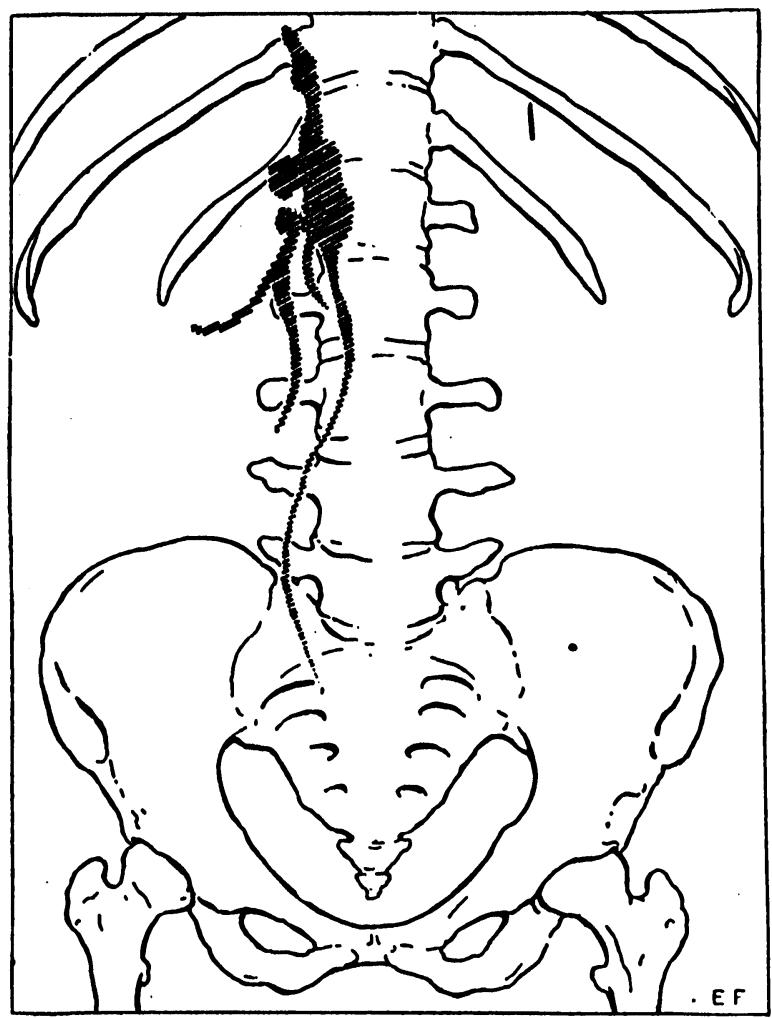

Fig. 4.-Flattening und median deviation of pelvis by laterallying tumor, with retraction of callces.

insufficiency; (6) evidence of thrombosis. It must be remembered that metastases may be found when the renal tumor is so small that it cannot be palpated clinically. Microscopic sections of superficial tumors may be the first to call our attention to the existence of hypernephroma. In a case which came under our observation recently a metastatic tumor was found in the rectum.

Results of Nephrectomy.-Of the sixty-one patients in whom nephrectomy was done, seven, or 11 per cent., died in the hospital. Of the remaining patients, we were able to trace fifty-one. Of these, ten were operated on less than a year before, seventeen were alive more than one year, twelve after three years, four after five or more years, and one after eight years. Of the twentyseven patients reported dead, nine died before one year after operation, two lived one year, four lived two years, and one lived three, four and five years after operation, respectively. Thus we have a three-year cure in fourteen, or 27 per cent., of the patients, and a five-year cure in five, or 10 per cent., of the patients. Of the patients that were reported alive three years or more the average length of symptoms noted prior to operation was $\mathbf{1 . 6}$ years. Of those who lived less than three years the average length of symptoms was 2.8 years. It is evident, therefore, that, as a general rule, the shorter the existence of symptoms prior to operation the better will be the prognosis. Furthermore, it is seen that results of neph- rectomy for renal tumor compare favorably with operations for malignancy elsewhere in the abdomen.

In conclusion I wish to emphasize the importance of immediately ascertaining the source of every hematuria. Of the fifty-three patients operated on for malignant renal tumor who had a definite history of hematuria, but eighteen, or 34 per cent., had been advised to be examined for its source. Hematuria, particularly when so well marked as to color the urine, is always to be considered a sign of some grave condition in the urinary tract. In fact, it would be conservative to regard every case of hematuria as the result of a malignant process until it can be definitely proved otherwise. Renal tumor may lie dormant or grow insidiously over a period of years and by the time that hematuria, tumor or pain calls attention to its existence, it should receive immediate surgical attention.

\section{REPLACING DEPRESSED FRACTURES OF THE MALAR BONE}

J. G. R. Manwaring, M.D., Flint, Mich.

In a recent report of a case of depressed fracture of the malar bone the operator mentioned the fact that he made an incision three-fourths inch long in the skin under the eyelid, drilled through the orbital crest of the malar bone, and then inserted a silk thread through the hole thus made to use as a tractor in replacing the depressed bone. This seems improper, since it scars the face, gives but imperfect control of the bone, and makes a longer and more serious operation of it than is necessary.

Others in similar cases advise drilling the body of the bone and inserting screws or gimlets for traction purposes. Others, again, open the antrum through the canine fossa and press out the bone from within with a suitable elevator; Murphy uses for this a rubber-covered instrument resting on the teeth as a fulcrum. While the last-mentioned method gives fair control of the bone involved, it necessitates an opening into the mouth, and disposes to infection.

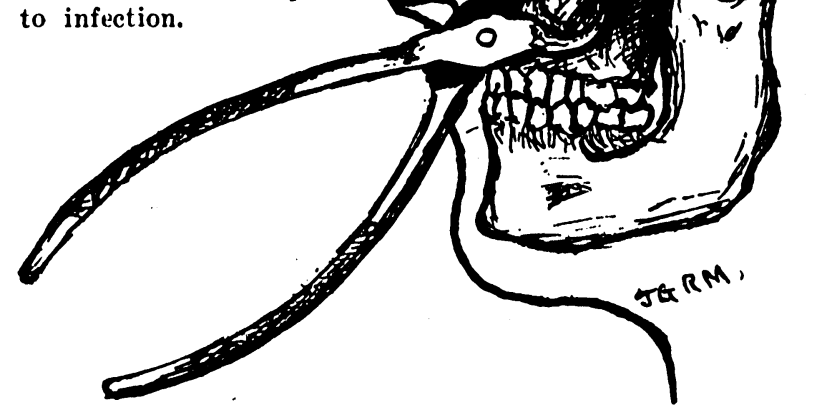

Replacing depressed fractures of the malar bone.

For elevating depressed fractures of the malar bone I have used an instrument always obtainable, the ordinary "cowhorn" forceps of the dentist, as shown in the illustration. The instrument is strong, and when properly used gives firm control of the bone better than the other methods. This is more readily appreciated when tried than would be believed from a mere description of its use. In addition to the sure control it leaves no scars, is quickly used, and does not enter through the mouth cavity.

The skin over the bone is suitably prepared; one point of the forceps is placed over the orbital ridge and the other just under the margin of the body of the bone at its outer side; 
little pressure penetrates the.skin, and the points grusp tho depressed bone with any degree of firmness advisable. Now the inore or less impacted bone is disengaged from its bed, elevated to its proper place, and the forceps removed at once. No dress. ing is necessary, as.the holes in the skin are mere pricks. The outline figure here shows crudely the forceps and the method of application.

\section{A PORTABLE COMBINATION DOUCHE-CAN AND STERILIZER}

Adam P. Leighton, JR., M.D., L.M. (Dublin), Portland, Maine

Believing that some of the readers of THE JoukNaL who are engaged in the practice of olstetries may be interested in a combination douche-can and sterilizer, I herewith give a plan

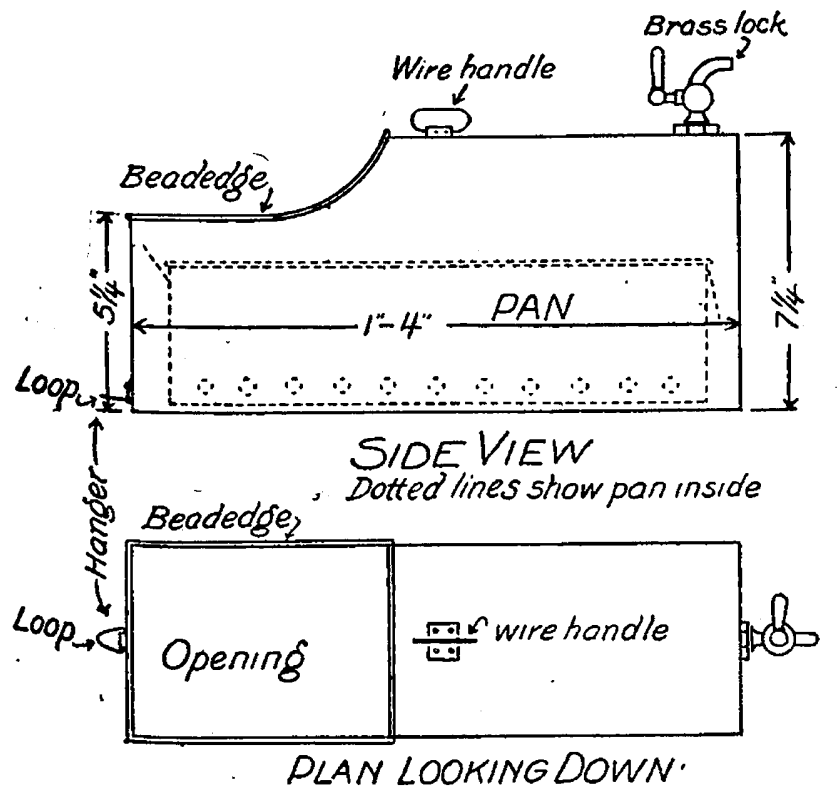

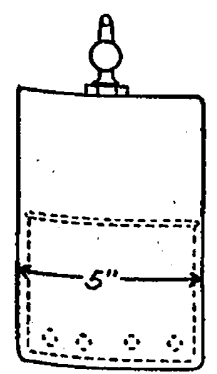

HIGH END

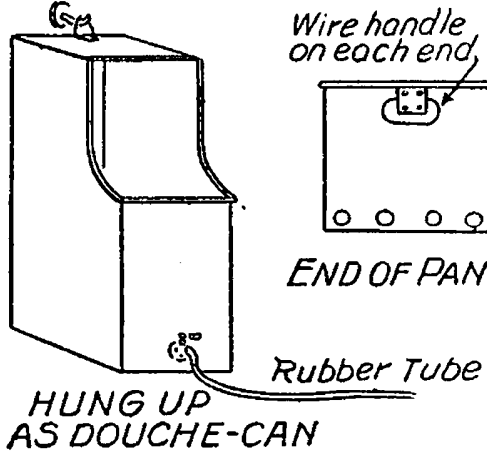

Comblnation sterilizer and douche-can. The sterllizer is of copper pollation sterilizer and douche-can. The sterllizer is of copIn the bottom of the pan and on the sldes are three-elghth-inch pertorations.

and description of one which to me is most satisfactory and practical.

It is easily carried in the ordinary 18- or 20-inch obstetric bag. Its width of 5 inches allows for ample room between the sides of the douche-can and the bag, where the bottles, pad, dressings and other obstetric necessities may be placed. In the douche-can may be placed the forceps, sutures, gloves and other instruments, so that all space in the bag is utilized.

The instruments, gloves, etc., are placed in the pan of the sterilizer and boiled, after which they are removed in the pan from the sterilizer. The brass cock, which is threaded and casily removed and which has been duly sterilized with the instruments, may be screwed into the sterilizer, and this in turn set on end or hung on a hook. The desired antiseptic being added to the boiled water, and a rubber tube, which also has been sterilized, being attached to the cock, makes ready a douching solution if needed.

I take no credit for originality in presenting this sterilizer and douche. It is nearly identical with Dr. Jellett's sterilizer and is in use in the extern department of the Rotunda Hospital, Dublin. I have simply changed the dimensions slightly and added handles, with a little different type of sterilizer pan.

192 State Street.

\section{A NEW INSTRUMENT FOR TEACHING THE AUSCUL- TATORY BLOOD-PRESSURE TECHNIC}

Francis Asmley Faugut, M.D., Pirmanelpuia

The accompanying illustration represents a new device to facilitate the teaching of blood-pressure readings by the auscultatory method. This method is now accepted as the most reliable and accurate clinical means of determining both the systolic and the diastolic readings, as by this method the results coincide with the figures obtained by the Erlanger graphic sphymomanometer.'

The chief drawback to the method has been the seeming difficulty which the average physician has in learning to perceive and interpret the sounds heard over the artery. The idea suggested itself that if the phrgmometroscope was made into a multiple of four, whereby the sounds could be heard by more than one indi-. vidual at the same time, it would overcome this difficulty and make it possible for any one familiar with the sounds heard during auscultatory blood-pressure obserrations to direct tlise attention of a small group of observers during the actual performance of the test. This has been done and the result has proved highly satisfactory. ${ }^{3}$ No difliculty resulied from the distribution of the sound through a larger tub-

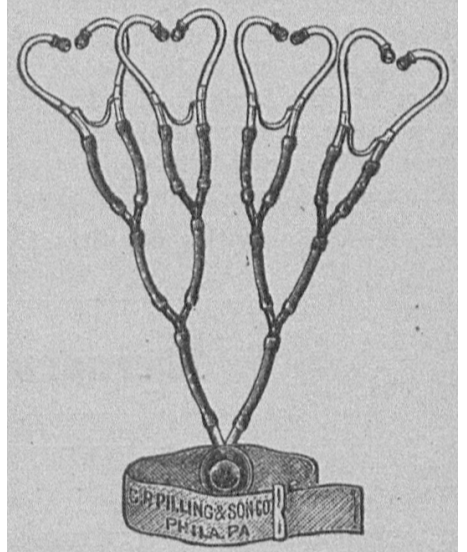

New instlument for teaching the auscultatory blood-pressure technic. ular system.

The device will be valuable particularly to the medical teacher, as it has been my experience that many ctudents go through their clinical studies without ever actually hearing or seeing a demonstration. It is applicable also in demonstrating to medical societies or groups of medical men conditions involving marked variations in pressure.

5006 Spruce Street.

\section{INFANTILE SCURVY IN WHICH SWOLIEN JOINTS RESEMBLED ACUTE ARTICULAR RHEUMATISM *}

Louis FIsches, M.D., NEw YoRK

The importance of selecting the proper food for an infant prompts me to demonstrate this case, which I shall term faulty feeding. It is caused by feeding canned foods in which the antiscorbutic factor is wanting. Human breast-milk is a live food which is decidedly antiscorbutic; therefore no infant fed on the human breast acquires scurvy. If we would imitate Nature we must feed cow's milk in such a manner that it is

1. Warfield, L. M. : Interstate Med. Jour., 1912, xix, 856.

2. The sphygmometroscope is a Bowles' stethoscope modifled and anted to use over the bifureation of the brachial al'tery.

3. Demonstrated before the Philudelphia Medical Literature Club, Nor. 22, 1912.

Case presented at meeting of Atlantic County Medical society. oct. 11., 1912. 